\title{
Structural transformations of innovative development and quality of life in modern environment
}

\author{
Vladimir Okrepilov ${ }^{1}$ and Natalya Gagulina ${ }^{1, *}$ \\ ${ }^{1}$ Institute for Regional Economic Studies Russian Academy of Sciences, 14, Leninsky prospect, \\ 119991, Moscow, Russia
}

\begin{abstract}
The research objective represented in the article was conducting an analysis of long-term transformation of the Russian economy, its manifestations and consequences, a detection of transformations of innovative development and its influence on quality of life of the population. The tasks which are, also, solved in the report: an analysis of the production structure of Russian gross domestic product in terms of the ration of the industries, types of activities in the field of the material production and service sector in an economy. The article highlights the key factors fuelling problems of the quality of life in the terms of an innovative development, the influence of cyclical economic development on structural transformations and quality of life is revealed. The methodological basis for studying the relationship between the innovative development of regions and the quality of life, as well as the practical application of the results obtained, was the economics of quality. The trend of lagging behind in the development of the knowledge economy, the annual decrease in domestic spending on research and development in the Russian economy, may contribute to the strengthening of regional differentiation, further increasing the social stratification of the population due to the fall in real incomes. The application of the methodological principles of the economics of quality makes it possible to use such mechanism for assessing the region's quality of life of the population, which allows not only to measure and standardize the quality of life indicator, but also to effectively use it for strategic management purposes.
\end{abstract}

\section{Introduction}

Accelerated implementation of innovations in public administration processes, in business process, especially, in people's daily lives, is accompanied by various transformations and becomes a factor that radically affects the quality of life of the population. In the era of the knowledge economy, new aspects of quality are revealing, allowing to take a new look at the classic problems of the economy, such as social inequality, unemployment, inflation, and economic and market failures. The research aimed at studying the structural transformations of the innovative development in the period of crises,

*Corresponding author: Nata_C@bk.ru 
identifying their possible impact on the quality of life has a particular relevance and, also, it is the component of the research objective, which results are presented in the article. The conceptual basis of the research is the methodology of the economics of quality both in metrology, standardization and quality management.

\section{Materials and methods}

Transformation is a phenomenon inherent in the economy at any level of its representation: global, national, regional, local, and in any context: industry-specific, structural or functional. Structural transformations are the most important manifestation of the economic transformation and are expressed in a change in the ratio of the sphere of material production and the sphere of services, have the form of shifts in the reproductive structure of the economy [1,2]. That is the reason why it is so important to pay special attention to the structural transformations of the innovative development.

During 1990-1999, the Russian economy underwent significant structural changes, which was reflected in the production of GDP. In 1990, 60.5\% of GDP was produced in the sphere of material production, 32.6-in the sphere of services, $6.9 \%$ were net indirect taxes. In 1998, $52.7 \%$ of GDP was produced in the service sector, $39.3 \%$ - in the field of material production and $8 \%$ were indirect taxes [3]. An analysis of the sectoral structure of Russia's GDP shows that the share of services increased not due to the growth of this sphere of activity, but due to a faster decline in the branches of material production.

The problems of presenting of statistical data of a methodological format greatly hamper the study of the structural transformations of the Russian economy. At the same time, methodological changes, reflecting the changes of the society's requests for necessary statistical information, in the formation of generalized indicators of economic development, generally, reflect the structural changes that have occurred over the past quarter of a century. For example, the allocation of such separate types of economic activities as An activity in the sphere of information and communication, Professional, scientific and technical activities, An administrative activity and related additional services, quite clearly demonstrates the changes in the industry structure of the Russian economy, due to the entry into a new technological order, the development of the knowledge economy and extensive digitalization.

To solve the problem of making comparable comparisons of the production structure of the Russian GDP of the 90s with the modern production structure, based on the methodological explanations of Federal State Statistic Service (section Methodology), by grouping, it is possible to consolidate the types of activities that formed a single group in the earlier database.

As the analysis of the production structure of Russian GDP in 2002-2020, presented in Figure 1, shows, the ratio of industries in the composition of GDP, which was formed at the end of the last century, has remained. In the period under review, on average, $33 \%$ of GDP was produced in the sphere of material production and more than $50 \%$ in the sphere of services. 


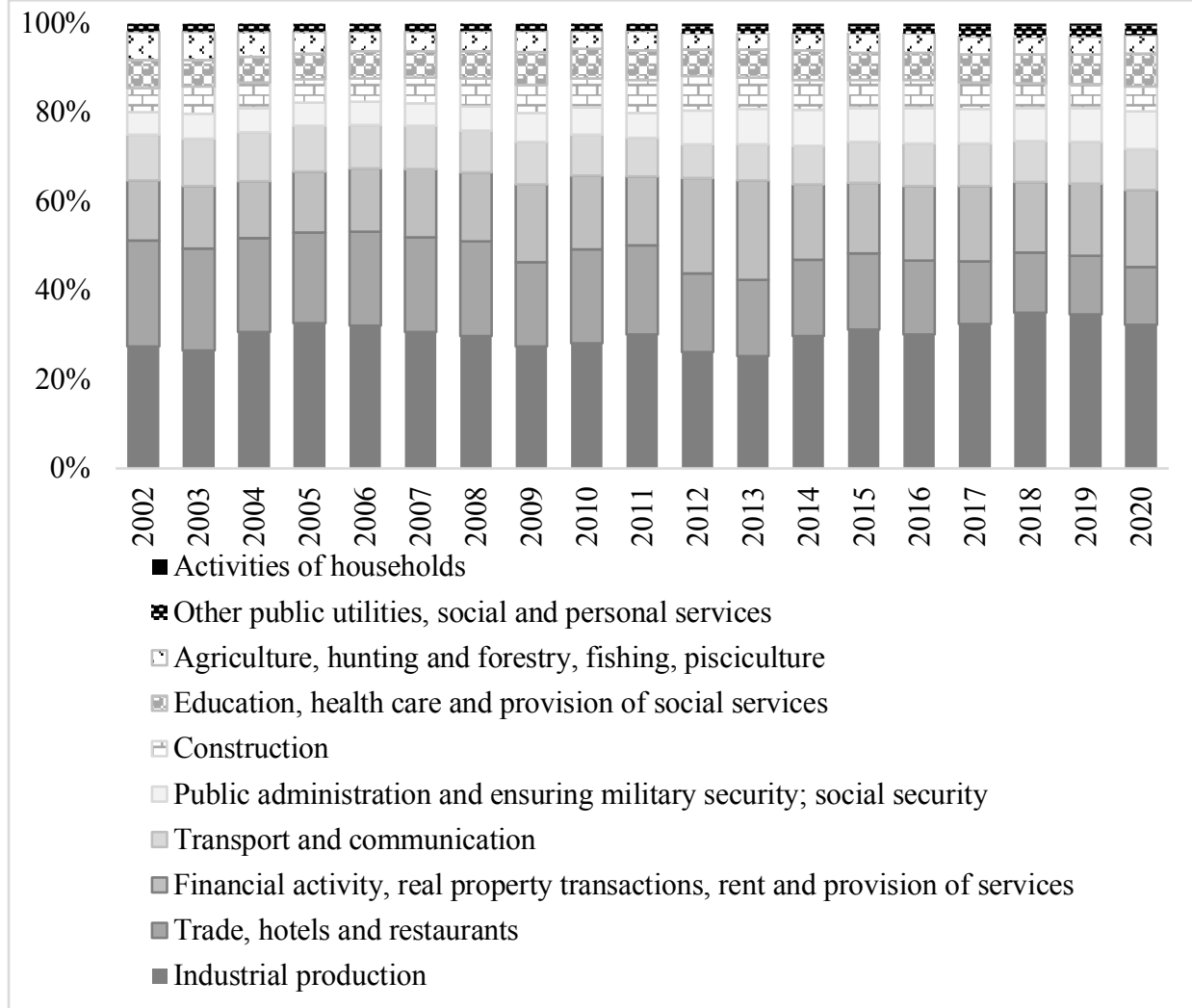

Fig. 1. The production structure of Russian GDP in 2002-2020.

In 2020, production in industry, agriculture, forestry, fishing, fish farming, and construction totaled $36.3 \%$ (Figure 2). The Industry has accounted for $32.2 \%$, followed by financial activity, real estate transactions, rent and service provision $(17.3 \%)$, trade, hotels and restaurants $(13.0 \%)$ - in third place.

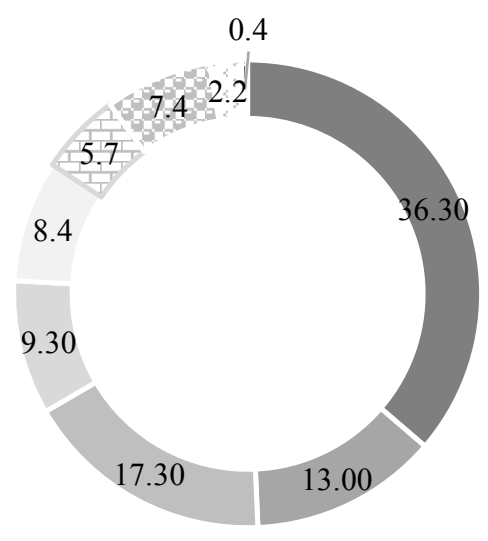

- Industrial production, agriculture, hunting and forestry, fishing, pisciculture

- Trade, hotels and restaurants

- Financial activity, real property transactions, rent and provision of services

- Transport and communication

Public administration and ensuring military security; social security

Construction

Education, health care and provision of social services

Other public utilities, social and personal services

Activities of households

Fig. 2. Industry structure of Russian GDP in $2020, \%$. 
As mentioned above, the current structure of Russian GDP is dominated by activities that are more typical for the service industries. In addition to structural changes in the production of Russian GDP, conducted grouping also allows us to identify its cyclical format with a period of 11 years. In our opinion, these medium-term fluctuations in the economic conjecture are associated with the frequency of renewal of fixed capital and the interaction of monetary factors in the financial sector of the economy. In general, the structural changes in the production of Russian GDP and the pronounced cyclical nature indicate the structural transformations of the innovative development. The growth of knowledge in the new stage of economic development has led to the fact that the processing and transformation of knowledge into new technologies and products has become a key factor in development. Also, it has led to the digital transformation of the economy [4]. The leading role in this process was played by the rapid virtualization of the financial sector of the economy. It was promoted by the accelerated development of the sphere of information technologies, means of communication and telecommunications.

The identified cyclicity in the development of the Russian economy allows to conduct a comparative analysis of the main economic and social indicators during the crises of 2009 and 2020. To do this, it is necessary to use the data from official sources: Federal State Statistic Service (section National Accounts) and the Bank of Russia (Report «Regional Economy: Comments of the Central Bank of Russia»).

Let's summarize the initial data in the Table 1.

Table 1. Key economic and social indicators during the 2009 and 2020 crises (increase over the previous year).

\begin{tabular}{|c|l|c|c|c|c|}
\hline \multirow{2}{*}{ № } & \multicolumn{1}{|c|}{ Indicator } & \multicolumn{3}{c|}{ Years } \\
\cline { 3 - 6 } & & $\mathbf{2 0 0 8}$ & $\mathbf{2 0 0 9}$ & $\mathbf{2 0 1 9}$ & $\mathbf{2 0 2 0}$ \\
\hline 1 & The index of physical volume of GDP, \% & 5.6 & -7.9 & 2.0 & -3.1 \\
\hline 2 & Industry, \% & 2.1 & -10.8 & 3.4 & -2.9 \\
\hline 3 & Investments in fixed capital, \% & 9 & -17 & 1.7 & -4.1 \\
\hline 4 & Construction, \% & 12.8 & -16.0 & 2.1 & 0.1 \\
\hline \multirow{2}{*}{5} & Freight turnover, \% & 0.7 & -10.2 & $\begin{array}{c}0.9 \\
\text { (January - } \\
\text { September) }\end{array}$ & $\begin{array}{c}-5.4 \\
\text { (January - } \\
\text { September) }\end{array}$ \\
\hline 6 & Retail trade, \% & 13.5 & -5.5 & 1.9 & -4.1 \\
\hline 7 & Real income, \% & 2.1 & 1.9 & 1.7 & -3.0 \\
\hline 8 & Number of unemployed, million people & 4.8 & 6.3 & 3.5 & 4.3 \\
\hline 9 & Unemployment rate, \% & 6.4 & 8.4 & 4.6 & 5.8 \\
\hline 10 & Inflation rate, \% & 13.3 & 8.8 & 3.0 & 5.2 \\
\hline & & -7.0 & 13.9 & $\begin{array}{c}3.6 \\
\text { (January - } \\
\text { September) }\end{array}$ & $\begin{array}{c}1.1 \\
\text { (January - } \\
\text { September) }\end{array}$ \\
\hline
\end{tabular}

Based on the dynamics of the key economic and social indicators, the crisis of 2009 , caused by the impact of the global financial and economic crisis, was more devastating for Russia than the crisis of 2020 due to the COVID-19 pandemic. In both cases, the impact was reflected in a reduction in the growth rate and production of GDP, and in the selected activities. However, in 2020, there was more significant fall in real cash income. Due to an $8.4 \%$ decrease in household spending on goods and services, final consumption expenditures decreased by $5.7 \%$. The consumer demand decreased mainly in non-food products and services. In the context of a fairly high level of unemployment, the current situation is an extremely unfavorable factor for the further innovative development of the economy. In addition, it threatens the achievement of a high quality of life of the population. 


\section{Results}

The problems of quality of life have been the subject of scientific research for many years, and are the goal and subject of the development management of countries and regions. Quality of life indicators are the basis for creating various ratings, both national and in comparison with foreign countries. Based on the results of the analysis, specific management decisions are made [5].

According to the analysis of the main macroeconomic performance indicators of the Russian economy in 2012-2019, the innovative economy of the Central, North-Western, Volga and Siberian Federal Districts is quite effective and is characterized by a high return on the investment in fixed capital. At the same time, in comparison with other countries, Russia has a tendency to lag behind in the development of the knowledge economy. Therefore, the annual decrease in internal research and development costs in the Russian economy may contribute to the strengthening of regional differentiation and further increase in the social stratification of the population. To prevent a potential decline in the quality of life of the population, it is necessary to use the most advanced forms and means of strategic management. In Saint Petersburg, for the first time in domestic practice, the concept of increasing the level of the knowledge economy in GRP was proposed. Besides, an action plan was developed, which is fixed at the legislative level. The quality economy has been used for many years to assess the quality of life and improve the living conditions and quality of life in the regions [6]. Within the framework of the author's methodology, a structural scheme for modeling the quantitative assessment of the quality of life of the population is proposed. A comparative assessment and analysis of the quality of life indicator for the subjects that are part of the North-Western Federal District was conducted. This methodology was developed at the Institute of Regional Economic Problems in the implementation of the Program of Fundamental Scientific Research of the State Academies of Sciences for 20132020 [7].

The quality economy makes it possible to take into account the factors of innovative development of regions at the highest, resulting level of quality by improving product quality, process quality, the quality of the activity organization.

On the conceptual basis of the Economics of quality to examine the relationship of regions' innovative development and the quality of life and for the practical application of the results obtained in the processes of regional strategies, it is necessary to use a mechanism for the quantitative assessment of the quality of life of the region's population. It allows to measure and standardize the quality of life indicator and effectively use it for strategic management purposes within a multi-level quality management system, using feedback systems (Figure 3). 


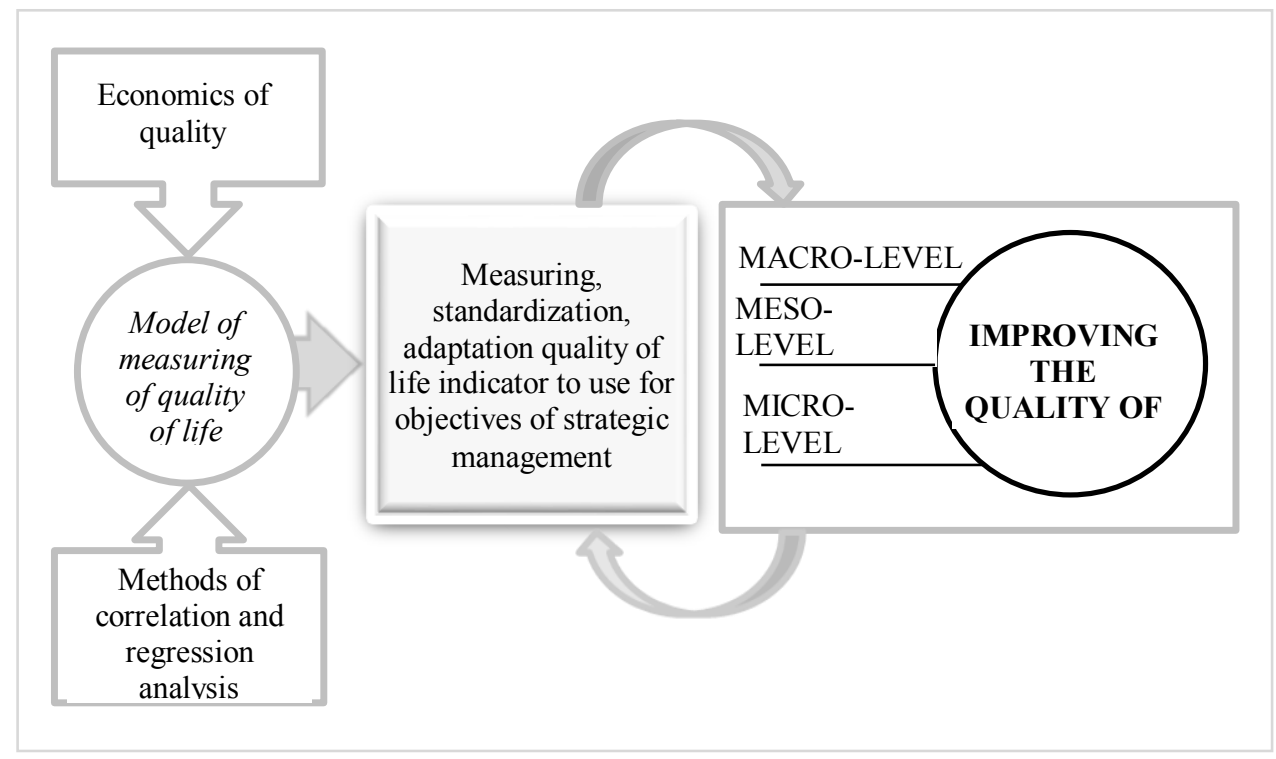

Fig. 3. Block diagram of modeling the quantitative assessment of the quality of life of the population.

Econometric models allow to reproduce the main properties of economic processes in order to obtain a prediction that serves as the basis for making managerial decisions to improve the quality of life. The quality of life can be improved only if the quality of processes occurring in the regional economy improves. To improve the quality of processes it is necessary to meet the required conditions. For instance, the main necessary condition for improving the quality of processes is increasing the receptivity of the environment to improvements [8]. Sufficient conditions for improving processes are the knowledge and ability of using of quality improvement tools by regional authorities.

The proposed model can become an effective tool both in the selection of strategic guidelines and methods of current management, and in the formation of their criteria and scales for assessing the quality of life. Since the model combines the requirements for the necessary quality of life and the definition of ways to meet them, it creates the prerequisites for increasing the effectiveness of regional management in the context of structural transformations of innovative development.

\section{Conclusion}

The study of transformations of innovative development based on the analysis of long-term changes in the structure of gross domestic product, the ratio of industries, activities in the sphere of material production and the service sector, and changes in the basic economic and social indicators in the period of crises, allows to select the specific transformations to trace the features of their impact on quality of life. The main difference between the 2009 crisis and the recent "corona"-crisis is a deeper fall in household incomes and an aggravation of the unemployment problem.

We can assume that the post-crisis economic recovery will be more "painful" and longer than a decade ago. Making forecasts is difficult, as the impact of the "corona"-crisis on the state of the economy has its own specifics. In our opinion, its consequences are more destructive than the impact of the 2009 crisis. About the identified problems, special attention should be paid to the search for suitable methods and tools to improve the quality of life of the population. According to the authors, the most optimal approach to the current situation 
is the approach developed on the conceptual basis of the Economics of quality. The economics of quality allows to form a strategic approach to assessing the quality of life, to correctly approach the development of further directions for improving the forecast scenario of the dynamics of the socio-economic system.

\section{Acknowledgement}

The article is prepared on the basis of the results of the basic research according to the Program of fundamental scientific research of the State Academies of Sciences for 20132020 .

\section{References}

1. A. Evmenov, I. Blagova, T. Sorvina, S. Kuzmina, Innovative development of the sociocultural sphere of the region (2019) DOI: DOI:10.1051/e3sconf/201911002060

2. S. Kuznetsov, D. Rodionov, M. Sviridenko, Y. Yakishin, Quality - Access to Success 22(180), 109-115 (2021)

3. N.V. Raskov, Makroekonomika Rossii (1990-1999 gg.) (SPbGU, 2001)

4. V. Okrepilov, S. Kuzmina, S. Kuznetsov, International Scientific Conference 'Digital Transformation on Manufacturing, Infrastructure and Service’ (DTMIS-2018) (2018)

5. I. Roshchina, E. Nekhoda, G. Kalyanova, E3S Web Conf. 174, 04052 (2020) DOI: 10.1051/e3sconf/202017404052

6. G. Getmanova, M. Smirnova, A. Yastrebov, Analysis of the relationship between quality of life and technological development of the regions of the Russian Federation. Materials of the international forum Metrological support of innovative technologies (St. Petersburg, 2020)

7. V. Okrepilov, N. Gagulina, Ekonomika Severo-Zapada: problemy i perspektivy razvitiya 2-3(61-62), 14-23 (2020)

8. D. Ahlstrom, J.-L. Arregle, M.A. Hitt, G. Qian, X. Ma, D. Faems, Managing technological, sociopolitical, and institutional change in the new normal (2020) DOI:10.1111/joms.12569 